\title{
JURISPRUDENCIA AMBIENTAL EN CASTILLA LA MACNHA (PRIMER SEMESTRE 2020)
}

\author{
NURIA MARIA GARRIDO CUENCA \\ Catedrática Derecho Administrativo \\ Universidad Castilla La Mancha
}


Sumario: 1. Procedimiento sancionador en materia de residuos. 2. Infracción en materia de aguas por supuesta manipulación de contador en un pozo: exigencias derivadas de los principios de presunción de inocencia, de culpabilidad y de responsabilidad. 3. El valor de la Declaración de Impacto Ambiental en una autorización ambiental integrada. 4.La naturaleza normativa de los Planes de Gestión de las zonas protegidas y la importancia de la publicidad adecuada de las normas ambientales.

\section{PROCEDIMIENTO SANCIONADOR EN MATERIA DE RESÍDUO}

La Sentencia del Tribunal Superior de Justicia de Castilla la Mancha de 27 de diciembre de 2019 (Sala de lo Contencioso-Administrativo, Sección 2, Ponente: Ricardo Estevez Goytre) (ROJ: STSJ CLM 3051/2019 - ECLI: ES: TSJ CLM: 2019:3051) resuelve la impugnación por la mercantil demandante del Acuerdo de 27 de julio de 2018 del Consejo de Gobierno de la Comunidad Autónoma de Castilla - La Mancha, que la sanciona con una multa de 45.000 Euros, por la comisión de vertidos de aspecto oleoso, considerada infracción muy grave según el art. 46.2.c) de la Ley 22/2011, de 28 de julio, de residuos y suelos contaminados.

La recurrente señala que el propio Acuerdo sancionador reconoce que "la pequeña cantidad generada, y ante la ausencia precisa del volumen de residuo vertido, y no teniéndose elementos probatorios suficientes para determinar una gran entidad en el vertido del residuo peligroso constatado, se consideró que los hechos denunciados eran constitutivos de una infracción grave del art. 46.3 o) de la misma Ley". Sin embargo, el Acuerdo sanciona a la recurrente en aplicación de la concurrencia de agravantes, por el impacto medioambiental del vertido realizado en una ZEC Ribera del Henares ES4240003 y la falta de inscripción de la mercantil como productor de residuos autorizado.

Señala el Tribunal que la principal cuestión a debate es la falta de prueba, pues hubo ausencia de toma de muestra del residuo oleoso y por tanto de su análisis, de modo que queda en entredicho la consideración de vertido de residuos peligrosos certificada por los funcionarios actuantes. Así, la recurrente alega que deben probarse tanto el vertido incontrolado de residuos como la peligrosidad de los mismos, extremos que no pueden quedar acreditados mediante la mera inspección ocular o la toma de fotografías. 
A juicio de la Sala, ha de acudirse "al caso concreto y valorar las pruebas o indicios para concluir si el vertido es o no susceptible de alterar perjudicialmente la calidad del agua". No se trata por tanto de actos que gocen de la presunción iuris tantum, "siendo precisa la existencia de prueba que así lo acredite, más allá de los casos en los que, por las características del vertido y notoriedad, esté implícito tal requisito". Como señala la Sentencia: "la Sala, cambiando su anterior criterio en materia de vertidos de aguas, considera, en sus más recientes pronunciamientos (por todas, la sentencia de 28 de diciembre de 2018, recurso 79/2018), que " ha de acudirse al caso concreto y valorar las pruebas o indicios para concluir si el vertido es o no susceptible de contaminar en los términos exigidos por el RDPH -alteración perjudicial de su calidad-; es decir, que no es suficiente con que la acción suponga una alteración de la calidad de las aguas, sino que es preciso, necesario, que la alteración sea perjudicial; y esto no se puede presumir, siendo precisa la existencia de prueba que así lo acredite".

El Tribunal termina considerando que existe conducta infractora a la luz de sendos informes que obraban en el expediente que reconocen la existencia de "agua aceitosa procedente de separadoras de agua/sustancias aceitosas", entendiendo aplicable el art.46.2 c) LRSC, aunque rebaja en un grado la calificación de la infracción predeterminada por la ley ante la insuficiencia de los elementos probatorios más precisos que hubieran determinado el daño efectivamente producido1.

\section{2.- INFRACCIÓN EN MATERIA DE AGUAS POR SUPUESTA} MANIPULACIÓN DE CONTADOR EN UN POZO: EXIGENCIAS DERIVADAS DE LOS PRINCIPIOS DE PRESUNCIÓN DE INOCENCIA, DE CULPABILIDAD Y DE RESPONSABILIDAD

La Sentencia número 305/2019, de 13 de diciembre, del Tribunal Superior de Justicia de Castilla-La Mancha, (Sala de lo Contencioso-Administrativo, Sección 2ª ) JUR\2020182256; ECLI:ES:TSJCLM:2019:3054) resuelve la adecuación a la legalidad de un procedimiento sancionador iniciado por la Confederación Hidrográfica del Guadiana por la que se impone una sanción de 4.999 euros por 
infracción del art. 116.3 ap. c/ y g), en relación con el artículo 55.4 del Texto Refundido de la Ley de Aguas, por manipulación del contador instalado en la captación del aprovechamiento, mediante la rotura del precinto de fábrica para evitar la alteración de la numeración que registra el totalizador. Este tipo de sanciones es bastante recurrente, por lo que la sentencia resulta de especial trascendencia.

La Sala entiende que existe una discrepancia básica entre los hechos imputados y aquéllos por los que se sanciona, en concreto "la manipulación del contador instalado en la captación del aprovechamiento del artículo 54.2 del Texto Refundido de la Ley de Aguas de referencia P-8234/2010, mediante la rotura del precinto de fábrica... ". Sin embargo, después la demandada no refiere tanto la infracción a la manipulación del contador, ni siquiera a quién se le puede atribuir la responsabilidad de la rotura del precinto de fábrica, como al hecho de que el interesado no comprobara inmediatamente tras las obras que el contador estaba debidamente precintado y que funciona; y la tardanza en comunicar tal situación a la $\mathrm{CHG}$. Por ello existe una infracción del principio de tipicidad de las normas sancionadoras.

También entiende vulnerados los principios de presunción de inocencia, de culpabilidad y de responsabilidad.

En primer lugar, al entender que la comisión de los hechos que se imputa, " la manipulación del contador mediante la rotura de precinto ", implica, "necesariamente, una actuación dolosa, intencionada; no cabe una conducta siquiera negligente o culpable; la rotura de precintos puede ser realizada culpable o intencionadamente (en este caso queda acreditado que fue accidentalmente al realizar un tercero obras de reparación); pero la manipulación de un contador, sea la forma en que se haga, implica, necesariamente, intención o propósito dirigido a un fin concreto: la alteración numérica que registra el totalizador, como así precisa la propia resolución impugnada”.

Sin embargo, de acuerdo al informe previo del Agente de Vigilancia, "no se ha sobrepasado el volumen de riego que tiene autorizado, no se ha producido un abuso de derecho y, por lo tanto, no hubo intencionalidad en la rotura del precinto, habiendo instalado el recurrente un nuevo contador, que ha sido 
precintado por la Comunidad de Usuarios el 12 de enero de 2.018, constando la documentación relativa a dicho contador en este Organismo ".

Es por ello que no concurre el elemento preciso de culpabilidad existente en esta infracción de "manipulación del contador", donde se concluye que "solo cabe la comisión dolosa, no la imprudente".

En segundo lugar, también se ha vulnerado el principio de responsabilidad, pues se achaca al cotitular de la concesión la manipulación del contador mediante la rotura de precinto, cuando del expediente y de la prueba practicada no solo no está acreditada tal circunstancia, sino más bien lo contrario. El mismo Agente señala en su informe: "no hubo intencionalidad en la rotura del precinto, pudiendo deberse la rotura a un golpe fortuito en las operaciones de reparación de la bomba ". Este alegato se pone en relación con la testifical del operario que realizó la reparación y que expresamente reconoció haber golpeado accidentalmente con la excavadora la bomba ocasionando la rotura del precinto. En consecuencia, no cabe imputar al actor la conducta, sentenciando la Sala que al hacerlo la Administración ha vulnerado principios básicos del procedimiento sancionador de presunción de inocencia, responsabilidad y culpabilidad.

\section{3.- EL VALOR DE LA DECLARACIÓN DE IMPACTO AMBIENTAL EN UNA AUTORIZACIÓN AMBIENTAL INTEGRADA}

La Sentencia del Tribunal Superior de Justicia de Castilla la Mancha de 23 de diciembre de 2019 (Sala de lo Contencioso-Administrativo, Sección 1, Ponente: Inmaculada Donate Valera) (ROJ: STSJ CLM 3006/2019 - ECLI: ES: TSJ CLM: 2019:3006) resuelve el recurso del titular de una explotación ganadera porcina frente a la desestimación presunta del recurso de alzada contra una Resolución administrativa que deniega la solicitud de autorización ambiental integrada (AAI).

El recurrente entiende viciada de nulidad la resolución, al haberse dictado prescindiendo total y absolutamente del procedimiento legalmente establecido en la Ley $21 / 2013$, de evaluación ambiental. Solicitando que se obligue a la Administración a formular una nueva declaración de impacto ambiental (DIA) que justifique la valoración de los efectos medioambientales del proyecto, motive las medidas de prevención, compensación y corrección de los efectos adversos sobre el medio ambiente y las medidas de vigilancia, seguimiento y sanción 
necesarias para cumplir con las finalidades de la legislación ambiental. Además, considera vulnerado el principio de igualdad, de seguridad jurídica y confianza legítima, comparando su situación a la de otra explotación porcina de similares características a la que se le concedió la AAI.

Sin embargo, la Sentencia entiende cumplida la motivación de la Resolución, en tanto explica la inviabilidad a efectos ambientales del proyecto en lid. Achacando al demandante que no hizo nada para rebatir los supuestos defectos en sede administrativa, por lo que no se le ha causado indefensión real ni material que conllevara la nulidad de la decisión.

Además, se señala que la previsión de las medidas solicitadas sólo es procedente en caso de viabilidad del proyecto. Esto es, en términos de la Sala: “...tras analizar la normativa sectorial que resulta de aplicación entendemos que las medidas correctoras y de prevención deben imponerse en caso de que se considere que el proyecto es viable desde el punto de vista ambiental. Sin embargo, en este caso el proyecto se ha considerado inviable desde el punto de vista ambiental por las razones que se esgrimen en la resolución que resuelve la declaración de impacto ambiental, por lo que no procede la imposición de medidas correctoras o de prevención (...) Es decir, las medidas correctoras y preventivas se imponen "si procede", para lo que es necesario, lógicamente, que el proyecto previamente haya sido declarado viable desde el punto de vista ambiental".

La sentencia también se detiene en recordar la naturaleza de la DIA como informe técnico que goza de presunción de acierto, y la importancia de la prueba pericial en caso de oponerse a su veracidad:

"la declaración de impacto ambiental es el informe que emite el Organismo Ambiental competente después de analizar el Estudio de Impacto, y es propiamente un informe técnico que goza de presunción de acierto, tratándose de auténtica pericia, y al obrar incorporados a aquél no precisa de ser sometido a un trámite especial de ratificación ( STS de 7 de marzo de 2006, rec. 3892/2003), debiéndose destacar la presunción de objetividad y acierto del mismo, alejado de los intereses de las partes, sin perjuicio lógicamente de que esa presunción de acierto y fiabilidad que pudiera atribuirse a los informes técnicos de la Administración obrantes en el expediente pueda desde luego ser 
destruida por los medios de prueba existentes en el procedimiento. En definitiva, el que un informe técnico emitido por un órgano administrativo goce de una fuerte presunción de neutralidad y acierto se debe, en relación al primero de los calificativos, a que, nacido de un órgano administrativo, ha de entenderse que fue emitido respetando el postulado de objetividad que el Artículo 103 de la CE proclama para la actuación de la Administración pública; y el segundo, por la solvencia técnica de quien lo emite.

En el caso de Autos, ha de reiterarse que los datos objetivos contenidos en la declaración de impacto ambiental y en virtud de los cuales se considera que el proyecto no es viable desde el punto de vista ambiental, no han sido desvirtuados por la parte actora a través de una prueba pericial".

Así mismo, entiende que no ha existido vulneración del principio de confianza legítima, pues la doble negativa a la solicitud elimina la posibilidad de interpretar que la Administración haya creado expectativa alguna de concesión de la AAI, ni menos que pueda entenderse que ha ido contra sus propios actos: "Sólo existe acto propio cuando concurre la expresión inequívoca de una voluntad de configurar de modo inalterable una relación o situación de derecho con eficacia frente a otras personas ( SSTS de 8 de febrero de 2005, 16 de febrero de 2005, 13 de octubre de 2005, 14 de octubre de 2005, 20 de octubre de 2005 y 28 octubre 2005) y el deber de coherencia con los actos propios sólo impide aquellos comportamientos que deben considerarse injustificados por consistir en la realización de actos posteriores contradictorios en su significación y eficacia jurídica con los primeros ( STS de 8 de noviembre de 2005).» ( STS del 22 de enero del 2013)... En este caso, la Administración no ha creado ningún tipo de expectativa de confianza y no se ha contradicho en la evaluación ambiental en ningún momento, pues siempre ha sido negativa, por lo que no ha existido vulneración de actos propios".

Finalmente, en relación con la vulneración del principio de igualdad consagrado en el artículo 14 de la Constitución, la Sala determina, por remisión a la doctrina del Tribunal Constitucional, que las explotaciones porcinas comparadas no se encuentran en situaciones subjetivas equiparables, término éste de comparación absolutamente necesario para apreciar la desigualdad invocada". Y lo justifica de este modo: 
“(...) Tal falta de identidad subjetiva, entre la autorización ambiental integrada concedida a la explotación porcina ubicada en Cardenete (Cuenca), y el proyecto de explotación porcina objeto del presente procedimiento viene, irremediablemente, determinada por la diferente ubicación, orografía y régimen de vientos. Difícilmente, puede constituir un término de comparación válido, y con ello considerar vulnerado el principio de igualdad, la autorización concedida por parte de la Administración a una explotación porcina en un término municipal distinto al que nos ocupa, en distinta provincia, y con distinta orografía y régimen de vientos. $Y$ todo ello sin que la parte actora haya intentado acreditar que existe identidad de condiciones y características entre ambas explotaciones".

\section{4.- LA NATURALEZA NORMATIVA DE LOS PLANES DE GESTIÓN DE LAS ZONAS PROTEGIDAS Y LA IMPORTANCIA DE LA PUBLICIDAD ADECUADA DE LAS NORMAS AMBIENTALES.}

La Sentencia del Tribunal Superior de Justicia de Castilla la Mancha de 2 de diciembre de 2019 (Sala de lo Contencioso-Administrativo, Sección 1, Ponente: Guillermo Benito Palenciano Osa) (ROJ: STSJ CLM 2836/2019 - ECLI: ES: TSJ CLM: 2019:2836) se dicta en un procedimiento análogo al resuelto en la Sentencia 1060/2019 del mismo orden jurisdiccional, que ya se comentó en la anterior Crónica.

En este caso, la asociación manchega de agricultores que impugnó la Orden 63/2017, de 3 de abril, de la Consejería de Agricultura, Medio Ambiente y Desarrollo Rural, por la que se aprobó el Plan de gestión de las Zonas de Especial Protección para las aves de ambientes esteparios, recurre ahora la Resolución de 20 de marzo de 2018 de la Dirección General de Política Forestal y Espacios Naturales, por la que se amplía el Anexo II de aquel Documento. La sentencia reitera la publicación incorrecta del Plan de Gestión, aunque se remita a las actuaciones posteriores de la Administración regional en ejecución del anterior pronunciamiento, en concreto: la publicación de la Orden 77/2019, de 22 de mayo, de la Consejería de Agricultura, Medio Ambiente y Desarrollo Rural, por la que se publicó íntegramente la Orden 67/2017; y la publicación de la Orden 83/2019, de 23 de mayo, de la Consejería de Agricultura, Medio Ambiente y Desarrollo Rural, por la que se procede a la publicación íntegra en el Diario 
Oficial de Castilla-La Mancha de la modificación y las ampliaciones del Anexo II del documento 2 del Plan de Gestión aprobado mediante la Orden 67/2017.

En base a la doctrina expuesta en su anterior pronunciamiento, también se anula la Resolución ahora recurrida, en base a las exigencias derivadas del carácter normativo de los planes en conexión con el principio de publicidad de las normas (artículo 52 de la Ley 42/2007 de 13 de diciembre, del Patrimonio Natural y de la Biodiversidad):

"(...) en la medida que estos planes de gestión prevalecen incluso sobre el contenido de planes urbanísticos, así como que en su función de desarrollo de los PORN les corresponde la zonificación concreta de los espacios, así como la determinación de las diferentes actividades que puedan desarrollarse en el mismo, entre otros contenidos, parece más que lógico considerar a los mismos planes como instrumentos normativos que por imposición del principio de publicidad de las normas deben ser objeto de publicación. Esto nos determina a considerar que la orden impugnada sí debe ser anulada al no publicar su contenido completo en el boletín oficial correspondiente".

Por tanto, "anulada la Orden 63/2017, necesariamente debemos también anular la Resolución de 20 de marzo de 2018, objeto del presente recurso, puesto que tiene por finalidad ampliar el Anexo II del documento 2 del Plan de gestión de zonas de especial protección para las aves de ambientes esteparios aprobado mediante la Orden 63/2017, de la Consejería de Agricultura, Medio Ambiente y Desarrollo Rural, y comete el mismo defecto de falta de publicación que se denuncia la misma parte recurrente en el presente litigio" .

Resulta relevante el carácter que el Tribunal atribuye a los planes de gestión, frente al argumento de la Administración que entendía que se trata de previsiones programáticas o de orientación a la gestión preventiva y activa mediante el diálogo y concertación. El Tribunal no duda en atribuir carácter normativo a estas previsiones y, en consecuencia, a la exigencia de su publicación, confirmada además en la propia normativa específica:

"Así el art. 3 de la Ley 42/2007, dentro de las definiciones, señala en el número 22, que bajo la denominación de instrumentos de gestión se incluye cualquier técnica de gestión de un espacio natural y de sus usos, que haya sido sometido 
a un proceso de información pública, haya sido objeto de una aprobación formal y haya sido publicado. Previsión que ha de ponerse en relación con las Directrices de Conservación de la Red Natura 2000 en España, aprobadas por Acuerdo de la Conferencia Sectorial de Medio Ambiente (reunión de 13 de julio de 2011) publicadas por Resolución de 21 de septiembre de 2011, de la Secretaría de Estado de Cambio Climático, Ministerio de Medio Ambiente y Medio Rural y Marino (BOE $n-244,10$ de octubre de 2011), conforme a las cuales se ha elaborado el Plan en litigio, según se recoge en su apartado 1.2, Directrices que en el apartado de aprobación, B.1, establecen que los instrumentos de gestión deben estar sometidos a un procedimiento de aprobación formal, que debe culminar con su publicación en el correspondiente Boletín o Diario Oficial, añadiendo en el apartado B.3, que una vez publicado oficialmente el instrumento de gestión, el órgano responsable en materia de Red Natura 2000 lo notificará al Ministerio de Medio Ambiente y Medio Rural y Marino, a efectos de su comunicación a la Comisión Europea. Previsión de publicación que responde a la naturaleza de la disposición administrativa y las exigencias formales derivadas de su alcance y contenido, de acuerdo con las normas comunitarias e internas a las que responden dichas Directrices.

Tal forma de publicación, por su alcance y contenido, no puede equipararse ni entenderse satisfecha en sus efectos por la remisión a la publicidad en otros medios, de acceso distinto e indirecto por parte de los destinatarios y afectados por la disposición, a salvo que la propia normativa reguladora del procedimiento de elaboración disponga esa forma específica de publicidad".

En fin, en cuanto al alcance del pronunciamiento en cuanto a su eficacia y validez, como ya se señaló en la anterior sentencia, la anulación se refiere a la Orden impugnada, por un vicio de la misma en cuanto no publica adecuadamente el Plan aprobado, de manera que "la validez del Plan no se ve afectada por el pronunciamiento, sin perjuicio de que mientras no se publique adecuadamente carezca de la eficacia que depende de dicha publicación oficial”. 